\title{
CRIANÇA E ADOLESCENTE CRONICAMENTE ADOECIDOS E A ESCOLARIZAÇÃO DURANTE A INTERNAÇÃO HOSPITALAR
}

\author{
CHRONICALLY ILL CHILDREN AND ADOLESCENTS AND SCHOOLING DURING HOSPITALIZATION \\ NIÑO Y ADOLESCENTE CON ENFERMEDAD CRÓNICA Y LA ESCOLARIZACIÓN DURANTE LA \\ INTERNACIÓN HOSPITALARIA
}

\author{
Mayara Kelly Moura Ferreira ${ }^{1}$ \\ Ilvana Lima Verde Gomes ${ }^{2}$ \\ Sarah Vieira Figueiredo ${ }^{3}$ \\ Maria Veraci Oliveira Queiroz ${ }^{4}$ \\ Viviane Peixoto dos Santos Pennafort ${ }^{5}$
}

Resumo Este artigo teve como objetivo identificar as propostas de escolarização no ambiente hospitalar, sua implementação direcionada às crianças e aos adolescentes cronicamente adoecidos e compreender a percepção deles acerca da sua escolarização nesse ambiente. Desenvolveu-se uma pesquisa em hospital de referência pediátrica de Fortaleza, estado do Ceará, no período de março a maio de 2013, por meio de entrevista semiestruturada, com oito crianças e adolescentes internados com condição crônica. Os dados foram submetidos à análise, elencando-se duas categorias: percepção de crianças e adolescentes hospitalizados acerca de sua escolarização; e distanciamento entre teoria e prática na escolarização de crianças e adolescentes hospitalizados. Observou-se que a tristeza emanada durante a internação das crianças e dos adolescentes, associada à saudade e ao afastamento da escola, as restrições impostas nas rotinas estabelecidas pela instituição e a condição clínica geraram imenso sofrimento nessas pessoas. Pouco se faz sobre a escolarização desses sujeitos, pois as atividades lúdicas e educativas efetivadas pelos profissionais da saúde não atendem a essa necessidade. Logo, concluímos ser essencial que a unidade hospitalar ofereça um acompanhamento educacional a essa clientela, dando continuidade ao processo de escolarização por meio da classe hospitalar, a fim de oferecer uma assistência integral atendendo às prerrogativas prescritas na legislação.

Palavras-chave escolaridade; doença crônica; assistência integral à saúde; criança hospitalizada; adolescente hospitalizado.
Abstract The purpose of this article was to identify the education proposals in the hospital environment, their implementation directed to chronically ill children and adolescents, and to understand their perception about their schooling in this environment. A survey was carried out at a pediatric referral hospital in Fortaleza, state of Ceará, Brazil, from March to May 2013, using semi-structured interviews and involving eight children and adolescents hospitalized because of a chronic condition. The data were analyzed and two categories listed: the view hospitalized children and adolescents have of their schooling, and the gap between theory and practice in the education of hospitalized children and adolescents. It was noticed that the sadness emanating during the children and adolescents' hospitalization, associated with nostalgia and distance from school, with the restrictions imposed by the routines established by the institution, and with patients' clinical condition generated immense suffering among these youth. Little is done about the education of these subjects, as the recreational and educational activities carried out by health professionals do not meet this need. Therefore, we conclude it is essential that the hospital offer this population educational follow-up, continuing the educational process through classes at the hospital in order to provide comprehensive assistance in view of the prerogatives prescribed by law.

Keywords education; chronic disease; comprehensive health care; hospitalized child; hospitalized adolescent. 


\section{Introdução}

A hospitalização na vida da criança e do adolescente traz um misto de sentimentos como tristeza, dor e esperança, entre outros. Os sentimentos de dor e tristeza ocorrem em razão do distanciamento do domicílio, dos amigos, das brincadeiras ou do colégio, ao mesmo tempo que ainda existe a esperança de cura ou melhora do quadro clínico e retorno às atividades cotidianas (Costa, Mombelli e Marcon, 2009).

Com a internação, surgem alguns aspectos desestruturantes para a criança e o adolescente, como a separação do lar e do convívio familiar, além dos procedimentos terapêuticos que podem agredi-los física e emocionalmente. Somado a isso está o fato de a rotina hospitalar muitas vezes não se adequar às suas necessidades de crescimento e desenvolvimento físico, cognitivo, social e biológico, por se constituir frequentemente em um ambiente planejado para a realização dos procedimentos assistenciais, sem ter em vista o bem-estar físico e mental dos seus pacientes (Araújo et al., 2011).

A criança e o adolescente em condição de adoecimento crônico lidam com constantes internações e reinternações, pois a cronicidade os torna dependentes de um acompanhamento contínuo nos serviços de saúde e de um suporte multiprofissional. A condição de adoecimento crônico infantil é conceituada como uma desordem com base biológica, psicológica ou cognitiva, com a duração mínima de um ano, e que produz uma ou mais limitações da função ou atividade, dependência de medicamentos, necessidade de dieta especial, aparelhos específicos, assistência pessoal e ainda de cuidados médicos, psicológicos e educacionais (Silva, 2001).

Em meio às constantes hospitalizações, essas crianças e esses adolescentes veem-se muitas vezes afastados do ambiente escolar, essencial para o seu processo de desenvolvimento cognitivo e social saudável (Cohen e Melo, 2010). Nesse contexto, considerando o prejuízo escolar causado pelas hospitalizações recorrentes ou prolongadas, a resolução n. 41/95, do Conselho Nacional dos Direitos da Criança e do Adolescente (Conanda), garantiu para essa parcela da população o "direito a desfrutar de alguma forma de recreação, programas de educação para a saúde e acompanhamento do currículo escolar, durante sua permanência no hospital" (Brasil, 1995).

O Ministério da Educação (MEC), por intermédio da Secretaria Nacional de Educação Especial, formalizou o atendimento educacional em classe hospitalar, afirmando que na impossibilidade de frequência à escola, durante o processo de tratamento em saúde ou psicossocial, os indivíduos precisam de estratégias alternativas de organização do ensino, de maneira a cumprir com os seus direitos de educação e saúde, preconizados na legislação brasileira (Brasil, 2002). 
A classe hospitalar é uma forma de atendimento pedagógico fornecida a crianças e adolescentes hospitalizados, internados em casas de apoio, ou ainda em ambientes domiciliares adaptados à assistência em saúde. Essa modalidade de atendimento teve início a partir do reconhecimento de que a hospitalização afasta esses jovens da rotina de uma escola, privando-os da convivência social e submetendo-os a riscos de transtornos ao seu desenvolvimento (Barros, Gueudeville e Vieira, 2011).

Desse modo, destaca-se que a hospitalização não deve ser vista como um rompimento do elo entre a criança/adolescente e a escola, nem a perda do direito de estudar. Logo, a classe hospitalar garante às crianças e aos adolescentes hospitalizados a oportunidade de continuarem a vivenciar as experiências pedagógicas, interligando a assistência em saúde com a educacional (Albertoni, Goulart e Chiari, 2011; Zombini et al., 2012).

Nesse sentido, torna-se importante investigar se as crianças e os adolescentes em idade escolar com condição crônica e que necessitam de internação para tratamento têm tido de forma efetiva um acompanhamento da educação formal dentro da instituição hospitalar, visando a um fortalecimento das discussões acerca dos direitos fundamentais da criança e do adolescente: saúde e educação (Brasil, 1991).

Destaca-se, portanto, que o cuidado oferecido às crianças e aos adolescentes hospitalizados não deve se restringir ao corpo doente, mas abranger esses indivíduos de forma integral, com suas necessidades biopsicossociais (Brasil, 2002). Ressalta-se que são incipientes as pesquisas sobre essa temática, o que torna o estudo relevante, pois mediante o conhecimento produzido espera-se sensibilizar os profissionais de saúde e gestores das instituições de saúde e educacionais para que eles reconheçam as necessidades de implementação da classe hospitalar - contribuindo, desse modo, para o desenvolvimento saudável da criança e do adolescente e propiciando um ambiente hospitalar mais humanizado.

Assim, os objetivos do estudo foram identificar as propostas de escolarização no ambiente hospitalar e sua implementação direcionada às crianças e aos adolescentes em condição crônica de adoecimento, além de compreender a percepção deles acerca da sua escolarização no ambiente hospitalar.

\section{Percurso metodológico}

Trata-se de uma pesquisa de natureza exploratória, 6 ancorando-se em uma abordagem qualitativa. A pesquisa exploratória tem a intenção de investigar aspectos de uma situação não conhecida para obter mais informações sobre o objetivo em estudo. A abordagem qualitativa se afirma no campo da 
subjetividade, com um universo de significados, crenças e valores. Com esse tipo de pesquisa, tenta-se compreender um problema na ótica dos sujeitos que o vivenciam, isto é, tem-se como ponto de partida a sua vida cotidiana, sua satisfação e seus desapontamentos (Leopardi, 2002; Minayo, 2010).

Escolheu-se como campo de pesquisa um hospital público estadual, de atenção terciária, direcionado exclusivamente à atenção infantil e do adolescente, referência em Fortaleza e em todo o estado do Ceará nessa área, com serviços de emergência, clínica e cirurgia em todas as especialidades.

Nesse hospital, os locais de internação são denominados, normalmente, de blocos, nomeados por letras do alfabeto ou especialidades. Escolhemos duas unidades que realizam atendimento nas especialidades de cardiologia, pneumologia, nefrologia e gastroenterologia. Cada unidade possui sete enfermarias, cada uma com quatro leitos e um leito separado para isolamento.

A pesquisa foi desenvolvida no período de março a maio de 2013. Participaram oito crianças e adolescentes com condição crônica de adoecimento internados na instituição pesquisada. Os critérios de inclusão foram: ter no mínimo oito e no máximo 19 anos, idade mínima estipulada para que os participantes compreendessem efetivamente os questionamentos das entrevistas; estar matriculado no ensino fundamental ou médio, ou já ter frequentado a escola; estar há no mínimo uma semana internado, de forma a se afastar do ambiente escolar; ter diagnóstico de doença crônica há mais de dois anos; ter mais de uma internação por ano, nesses dois anos de diagnóstico.

Foram excluídos crianças e adolescentes gravemente enfermos que não tinham condições de participar do estudo e aqueles que apresentavam algum distúrbio neurológico que os impossibilitasse de compreender as entrevistas. Os critérios foram escolhidos para se atingirem os objetivos propostos, de maneira que os sujeitos tivessem experiência com o processo de hospitalização e vivência com a cronicidade do seu adoecimento.

Para a coleta das informações, utilizou-se a entrevista semiestruturada, constituída por um item de identificação dos sujeitos e outro com perguntas norteadoras baseadas nos objetivos do estudo: o que você sente falta dentro do hospital em relação aos seus estudos? O que o hospital oferece a você em relação a sua escolarização? Como você se sente em relação a sua escola e aprendizagem? A entrevista semiestruturada permite que o entrevistado tenha possibilidade de discorrer sobre o tema sem se prender à pergunta formulada (Minayo, 2010). Todas as entrevistas foram gravadas e transcritas somente pelas autoras.

Ressalta-se que algumas precauções foram adotadas a fim de proteger a identidade dos participantes. Assim, identificamos os sujeitos pela letra do alfabeto ' $\mathrm{E}$ ', que significa entrevista, e numeramos conforme a ordem cronológica de realização, omitindo a real identidade dos sujeitos. 
Após a coleta dos dados, as entrevistas foram transcritas e examinadas exaustivamente, dispostas lado a lado, quando foi possível se perceberem as semelhanças e divergências. Utilizou-se lápis colorido para sublinhar as semelhanças com a mesma cor, e as divergências com outra. Em seguida, agruparam-se as informações destacadas, elencando-se duas categorias: percepção de crianças e adolescentes hospitalizados acerca de sua escolarização; e distanciamento entre teoria e prática na escolarização de crianças e adolescentes hospitalizados.

Preconizando a ética em pesquisa, o estudo seguiu todas as normas da resolução n. 466/12 da Comissão Nacional de Ética em Pesquisa, que determina o respeito à autonomia dos sujeitos, a beneficência, a não maleficência e a justiça (Brasil, 2012). Ademais, todos os sujeitos foram informados sobre a pesquisa, e depois de lido o termo de consentimento livre e esclarecido para os responsáveis e o termo de assentimento para as crianças e os adolescentes. Mediante a concordância, todos assinaram os documentos, cientes de que poderiam desistir a qualquer momento.

\section{Caracterizações das crianças e dos adolescentes}

Dos oito entrevistados, a maioria era do sexo feminino (cinco). Quanto à faixa etária, esta variou de 10 a 17 anos. Em relação à procedência, três residiam em cidades no interior do estado do Ceará, quatro na capital (Fortaleza) e um na região metropolitana. No que diz respeito à escolaridade, metade dos sujeitos frequentava a escola (pública ou particular), e a outra metade não estava estudando, mas já havia frequentado a escola anteriormente.

O tempo de diagnóstico da doença variou de dois anos e um mês a dez anos, com a predominância de três anos. Os diagnósticos foram: fibrose cística, síndrome do intestino curto, síndrome nefrótica, insuficiência renal crônica e miocardiopatia congênita. Todas representam condições crônicas que implicam reinternações periódicas e muitas vezes prolongadas - entretanto, não impeditivas ao ato de estudar.

Considerando-se a idade atual da criança/adolescente, a idade em que foi diagnosticada sua doença e o nível escolar em curso, cinco dos oito encontravam-se atrasados quanto à sua escolaridade - ou seja, estavam cursando série inadequada para a sua faixa etária, conforme os parâmetros preconizados pelo MEC, consoante a lei n. 9.394/1996, que estabelece as diretrizes e as bases da educação nacional (LDB) (Brasil, 2014).

Desse grupo de cinco crianças/adolescentes, quatro não frequentavam mais a escola. Dos quatro, dois já estavam em atraso escolar antes de pararem de estudar. Quanto aos outros dois, a perda de conteúdos e os afastamentos 
regulares da escola, motivados pelas frequentes internações, fizeram com que estacionassem no processo de escolarização. As demais crianças estavam conseguindo dar continuidade aos estudos, em detrimento dos atestados médicos usados para justificar as faltas e com a compreensão da direção escolar, que permitia em outro período a realização das avaliações perdidas.

\section{Percepção de crianças e adolescentes hospitalizados acerca de sua escolarização}

Por meio dos relatos das crianças e dos adolescentes, foi possível observar suas experiências com o adoecimento e a hospitalização, verificando-se o sofrimento gerado durante esse processo, o que implicou sentimentos de tristeza e angústia, como ilustra a fala a seguir:

É bem chato estar aqui. Apesar de você saber que vai sair melhor, você passa um bom tempo para conseguir essa melhora. Demora bastante, e você fica ansiosa para sair, às vezes dá até uma tristeza, uma vontade de chorar porque quer ir logo para fora (E7).

A hospitalização os afasta da vida cotidiana, da família, da escola e dos amigos, promovendo um confronto com a dor, limitação física e passividade, ocasionando uma ruptura do seu estilo de vida, submetendo-os à necessidade de readaptação como pacientes às normas e rotinas do serviço, que são estabelecidas sem a sua consulta (Zombini, 2011). Todas essas mudanças nos hábitos de vida, os procedimentos e rotinas aos quais a criança e o adolescente são submetidos podem se tornar, muitas vezes, experiências traumáticas para esses indivíduos.

Observou-se que essa experiência hospitalar tende a provocar maior impacto negativo quando ocorre o total afastamento da criança e do adolescente do processo de ensino-aprendizagem escolar, pois a escola e as atividades educativas se mostraram como de grande representatividade para essas pessoas, por serem algo bastante prazeroso e gerador de novos conhecimentos.

Evidenciou-se nas expressões das crianças e dos adolescentes o quanto foi difícil para eles, durante o período de internação e adoecimento, ficar sem estudar e aprender novidades. A tristeza e a saudade foram os sentimentos mais evidentes.

Para mim é difícil ter que faltar aula, bastante, porque eu gosto muito de estar na escola, gosto de estudar, gosto de estar aprendendo (E7).

É ruim porque atrapalha muito, se eu estivesse na escola era melhor (...). Fico triste porque eu estou perdendo; no lugar de eu estar ganhando, estou perdendo (E1). 
Me sinto mal (...) por deixar de estudar. (...) Eu acho muito bom estudar (E5).

Triste, eu queria ir para casa, para ficar lendo e escrevendo, porque eu quero estudar de volta (E8).

Essa problemática também foi destacada em outra pesquisa sobre a escolarização no ambiente hospitalar, na qual se encontraram, nas expressões dos familiares, os pedidos angustiados das crianças e dos adolescentes para retornar ao ambiente escolar e ter a possibilidade de continuar a frequentar as atividades educativas. Esse afastamento também foi visto de forma amplamente negativa pelas crianças e pelos adolescentes e seus acompanhantes (Holanda e Collet, 2012).

Por serem acometidos por uma condição crônica, são comuns situações de complicações, intercorrências e melhoras no estado clínico, com a necessidade de um constante acompanhamento e tratamento médico. Muitas vezes, mesmo quando não estão hospitalizados, com o agravamento da enfermidade, a criança e o adolescente adoecidos acabam se vendo obrigados a se ausentar por alguns dias da escola até o seu restabelecimento clínico, circunstância também difícil para essas pessoas.

(...) quando eu tenho que faltar aula por causa de alguma coisa, quando não estou me sentindo bem, aí eu fico mais triste (E7).

Em outro estudo, observou-se o terror para alguns dos entrevistados em se ausentarem da escola em detrimento do seu adoecimento crônico, mostrando o quanto as crianças valorizam o espaço escolar e se esforçam para não se afastarem de suas atividades (Borba et al., 2009).

Outra importante percepção emanada dos depoimentos revelou o sentimento de exclusão vivenciado por uma criança que se via fora do padrão considerado normal pela sociedade de frequentar a escola, já que em razão de sua condição crônica essa atividade era bastante dificultada, impossibilitando-a de dar continuidade aos estudos, principalmente diante das numerosas e prolongadas internações durante o ano.

Eu me sinto excluído, como se eu não fosse um menino normal, não poder estudar, não poder sair de casa porque eu tenho a imunidade baixa, aí eu me sinto excluído da comunidade (E2).

Observou-se, em outro estudo, que os longos períodos de internação se mostravam limitantes à escolarização e à socialização, o que era reconhecido pelas crianças e pelos adolescentes. Estar fora da escola também significava para eles estarem excluídos de um espaço de troca e aprendizagem, aspectos 
que geravam saudade e ansiedade nessas pessoas (Holanda e Collet, 2012). Nesse contexto, destaca-se que a continuidade do processo de escolarização dentro do hospital, além de ajudar a criança a superar esse período, contribui para que ela se sinta incluída na sociedade, reduzindo a sensação de estar sendo punida pelo fato de ter uma condição crônica de adoecimento (Holanda e Collet, 2012).

A saudade da escola, dos estudos, das novidades, dos professores, colegas de sala de aula, de algumas disciplinas, e até mesmo de fazer as tarefas de casa e as provas, também foram destacadas nas falas:

É ruim. Sinto saudade da escola, de estar com os amigos na escola estudando (E3).

Eu sinto saudade é de fazer o dever e a prova (E4).

Eu sinto falta dos meus estudos, dos meus amigos (...) do aprendizado (E5).

Ah, de matemática, pintar (...) aula de espanhol, matemática, português, só, é o que gosto mais. As matérias que eu gosto mais são essas (E6).

(...) da minha escola, todo dia eu ia. Eu gostava também dos professores (E2).

A escola, além de ser um campo de ensino e aprendizagem, é comprovadamente um espaço de socialização imprescindível para crianças e adolescentes, além de ser a primeira instituição de contato interpessoal em um ambiente fora do contexto familiar, contribuindo para a formação da identidade dessas pessoas (Schneider e Martini, 2011). Notou-se também, por meio dos relatos, que durante a internação o sofrimento acentua-se com a perda desse convívio social tão marcante na escola, pois apesar de estarem rodeados por profissionais de saúde, familiares e outras crianças e adolescentes, não existe no contexto hospitalar um local propício para melhor interação entre essas pessoas - por muitas vezes se tratar de um ambiente técnico, com recursos humanos e estruturais que visam apenas ao restabelecimento da saúde física dos indivíduos.

O único contato que a gente tem aqui dentro com as pessoas é com as enfermeiras ou com os outros pacientes, sendo que a gente não pode tá muito perto deles (...) eu sinto falta da escola, dos professores, sinto falta de conversar com outras pessoas, sinto falta do convívio com os outros alunos, meus amigos, sinto bastante falta disso (E7).

Uma característica marcante da fase escolar é o anseio em realizar novas descobertas, aprender algo novo e enfrentar desafios. Nesse sentido, dois dos escolares referiram que a hospitalização não oferecia oportunidades 
nem estímulos para o seu aprendizado, o que gerou uma sensação de estagnação cognitiva e sentimento de falta da escola.

Eu estando aqui não estou estudando (...) se eu estivesse na escola, estava aprendendo cada dia mais coisas novas (E1).

Sinto falta de estar aprendendo coisas novas, de estar usando minha cabeça pra tentar aprender coisas novas, de me autoestimular, tentar superar meus limites, aqui não faço isso muito (E7).

Para as crianças e os adolescentes em condição crônica de adoecimento que enfrentam períodos de internação frequentes, o hospital permeia o seu processo de crescimento e desenvolvimento, limitando-os, muitas vezes, social e intelectualmente (Araújo et al., 2009). Assim, essas pessoas acabam sentindo-se afetadas por tal perda, o que gera sentimento de retrocesso quanto ao seu aprendizado, preocupação e angústia, fatores que afetam o estado da criança e do adolescente.

Eu estou desaprendendo muito, estou perdendo (...) estava sabendo que eu não ia perder esse ano, e acho que esse ano eu vou perder porque está quase com um mês que não estou indo pra aula (E1).

Um estudo semelhante foi realizado com adolescentes acometidos de doenças crônicas. Os pesquisadores constataram que eles demonstraram tristeza ao falar dos períodos de afastamento da escola por causa da doença. Nesse estudo, os adolescentes se mostraram preocupados com a perda do ano letivo, já que eles não tinham alternativas disponíveis para continuar desenvolvendo suas atividades escolares durante a hospitalização (Schneider e Martini, 2011).

Ressalta-se que os prejuízos escolares ocasionados pela perda do ano letivo ou interrupção da escolarização são fatores que podem repercutir negativamente na vida adulta de crianças e adolescentes, o que reforça a necessidade de que durante a hospitalização exista maior preocupação com o acompanhamento escolar dos pacientes por parte dos gestores hospitalares e das instituições escolares (Holanda e Collet, 2012).

\section{Distanciamento entre teoria e prática na escolarização de crianças e adolescentes hospitalizados}

Por meio dos depoimentos das crianças e dos adolescentes, foi possível discutir também acerca das carências e iniciativas existentes na instituição em 
estudo, relacionadas ao processo de escolarização desses pacientes. Observou-se que quase nada tem sido desenvolvido visando fornecer condições para que essas pessoas pudessem dar continuidade às suas atividades escolares dentro do ambiente hospitalar, exceto por algumas dinâmicas lúdicas realizadas por profissionais de saúde, que pouco se aproximam do processo de ensino-aprendizado escolar. Essa realidade foi evidenciada nos relatos a seguir:

(Risos) Nada. Só traz desenho pra gente pintar (...) enquanto se eu estivesse na escola, eu estava aprendendo (E1).

Não deram suporte ainda no hospital. Não dá nada, só tem mesmo a terapeuta ocupacional, só pintura, pintura de gesso (E2).

Eu só pinto aqui, mais nada, só pintura. A mulher vem aqui e deixa aqui para nós pegar (E6).

Essa falha no serviço hospitalar também pôde ser visualizada em outra pesquisa, na qual os autores apuraram, por meio dos relatos dos acompanhantes de crianças e adolescentes hospitalizados com doenças crônicas, que a instituição pesquisada não estava preparada para acolher as necessidades intelectuais e educacionais dos pacientes. Ademais, embora houvesse um trabalho coordenado por pedagogos, as famílias não conseguiram percebê-lo como uma atividade de promoção do acompanhamento do currículo escolar, por essas atividades priorizarem o aspecto lúdico, insuficiente para atender às reais necessidades de escolarização e socialização dos pacientes (Holanda e Collet, 2011).

O desenho, a pintura, os brinquedos oferecidos pela terapeuta ocupacional e as intervenções terapêuticas realizadas por essa profissional estiveram presentes, nos depoimentos da maioria dos entrevistados, como as que mais se assemelhavam às praticadas na escola. Entretanto, apesar de ser lembrada pelas crianças e pelos adolescentes, essa profissional não teve sua função compreendida pelos pacientes, a qual vai muito além do lúdico, por se tratar de ações com embasamento científico e que visam a resultados terapêuticos que contribuam para o restabelecimento da saúde das crianças e dos adolescentes.

Aqui tem a terapeuta ocupacional que dá desenho pra gente pintar e pra gente não ficar sem fazer nada. E é bom porque a gente se ocupa com alguma coisa (E3).

Dá aqueles livrinhos pra ler, (...) ela dá livrinho pra ler, coisa pra pintar, dá brinquedo, balão (E4).

A única coisa que eu vejo que eles oferecem mais aqui é a terapeuta ocupacional (E7). 
Observou-se que as atividades que envolviam a pintura, o desenho, os livros e o lúdico contribuíram positivamente no processo de enfrentamento da internação das crianças e dos adolescentes, que por alguns momentos tiveram a oportunidade de se desligarem das rotinas hospitalares e se descontraírem. No entanto, salienta-se que isso não tem sido o suficiente para suprir as suas necessidades educacionais e os seus direitos preconizados na legislação brasileira referentes à resolução n. 41/95 (Brasil, 1995), pois apenas uma parte tem sido seguida na instituição pesquisada, no que diz respeito às atividades de lazer e recreação.

Nesse contexto, reafirma-se que a estratégia das classes hospitalares criada pelo MEC se apoia em propostas educativas e escolares que se diferenciam das atividades lúdicas e recreativas - pois ainda que o lúdico também seja considerado uma tática de aprendizagem utilizada no hospital, a intervenção pedagógica educacional é mais específica, por ser individualizada e ter responsabilidade com o aprendizado formal dessas crianças (Zombini et al., 2012).

Nessa perspectiva, destaca-se a importância de haver uma preocupação quanto à faixa etária e às capacidades cognitivas dos pacientes em relação ao processo de ensino-aprendizagem, bem como ao grau de escolaridade já vivenciado anteriormente, de forma que a escolarização no contexto hospitalar ocorra de maneira efetiva e com qualidade, abrangendo as necessidades específicas de cada criança e adolescente. Assim é a fala de um dos escolares, ao expressar sua insatisfação quanto à utilização dos desenhos na instituição:

Se estivesse na escola, tinham outra coisa pra ensinar, porque aqui só traz desenho; desenho não ensina nada, (...) isso aí eu faço na creche, eu já estou na $8^{a}$ série (E1).

Ressalta-se que um dos entrevistados falou a respeito de um projeto de humanização oferecido pelo hospital, a 'Cidade da Criança', espaço recreativo para os pacientes, separado das enfermarias, com brinquedos e materiais lúdicos. Entretanto, esse entrevistado também enfatizou que, apesar de ser um local importante na lida com a hospitalização, por possibilitar momentos de lazer, não tinha as funções educativas e interacionais existentes na escola.

De vez em quando a gente vai para a 'Cidade da Criança'. Lá tem alguns jogos ou brincadeiras, ou atividades que fazem a gente interagir um pouco com as outras crianças e agir um pouco como se estivesse na escola, mas não é a mesma coisa, não. Sinto falta de estar aprendendo. Lá a gente só faz mesmo é desprender um pouco dessa coisa chata que é estar no hospital (E7).

Apesar de não terem sido identificados nas falas, ressalta-se que o hospital em estudo desenvolve alguns projetos de apoio pedagógico. Dentre 
eles está o $\mathrm{ABC}+$ Saúde e o Soletrandohias. De acordo com os profissionais desse serviço, o projeto $\mathrm{ABC}+$ Saúde atende às demandas surgidas no serviço por meio de queixas dos familiares acompanhantes em relação ao déficit de aprendizagem dos seus filhos, que permaneciam longos períodos hospitalizados, afastados da escola e do convívio social. Criado com a finalidade de oferecer apoio pedagógico às crianças e aos adolescentes com câncer internados na instituição, o ABC+Saúde existe desde 1995 e desenvolve atividades que estimulam o pensamento crítico, a curiosidade e o raciocínio, além de integrar acompanhantes no processo de ensino-aprendizagem em educação ambiental, higiene e cuidados especiais com o paciente. A equipe realiza atividades educativas, previamente elaboradas, e as aplica na sala de convivência $\mathrm{ABC}+$ Saúde ou à beira do leito do paciente. São atividades escolares, lúdicas e artísticas que podem ser realizadas em grupos ou individualmente (Hospital Infantil Albert Sabin, 2013).

O projeto funciona em parceria com a Universidade Estadual do Ceará, a Universidade Federal do Ceará e a Universidade de Fortaleza - recebendo alunos de graduação das diversas licenciaturas e da especialização em psicopedagogia - e com a pós-graduação da Universidade Vale do Acaraú. O atendimento se dá na unidade onco-hematológica, nos períodos da manhã e da tarde. A coordenação é do serviço social, com acompanhamento e orientação da psicopedagogia (Gomes, 2007).

Quanto às crianças e aos adolescentes hospitalizados por outras patologias, objeto deste estudo, existe o projeto Soletrandohias, iniciado em maio de 2005, que oferece apoio pedagógico e psicopedagógico às crianças na faixa etária de 6 a 14 anos internadas (Gomes, 2007). Este projeto teve seu funcionamento prejudicado devido às reformas no hospital, conforme relato de alguns profissionais da instituição - pois após as alterações estruturais, o espaço onde esse projeto era desenvolvido foi transferido para outro local, distante das unidades de internação, o que tem dificultado o acesso/deslocamento dos pacientes.

Neste estudo, percebeu-se que as crianças, os adolescentes e seus familiares não tinham conhecimento desse projeto, haja vista que não foi citado em seus depoimentos, tampouco pelos pais em conversa informal. Entende-se que esse apoio lúdico-terapêutico é fundamental, mas insuficiente diante do que realmente preconiza a classe hospitalar: apoio pedagógico em nível curricular, isto é, toda atividade pedagógica realizada no hospital deverá ser incluída no currículo da criança, contribuindo para a diminuição das reprovações e da evasão escolar (Zombini et al., 2012).

São exigências do MEC para o funcionamento da classe hospitalar: uma sala para desenvolvimento das atividades pedagógicas com mobiliário adequado e uma bancada com pia, instalações sanitárias próprias e espaço ao 
ar livre adequado para atividades físicas e ludopedagógicas. Além desse espaço próprio para a classe hospitalar, o atendimento pode desenvolver-se nas enfermarias, nos leitos ou no quarto de isolamento, caso haja impedimento pela condição clínica ou de tratamento do escolar (Brasil, 2002).

O professor da classe hospitalar deve articular-se com a equipe de saúde do hospital, com a Secretaria de Educação estadual ou municipal, e com a escola, contribuindo para o restabelecimento da saúde e garantindo, por meio do cumprimento da grade curricular, a continuidade dos estudos e a aprovação da criança para o próximo ano letivo (Zombini et al., 2012).

Ante a hospitalização da criança ou do adolescente, é necessário que os profissionais de saúde e gestores reflitam sobre sua prática e passem a se sentir inquietos e incomodados com essa situação, a ponto de se verem compelidos a procurar novas estratégias de atuação para mudar esse cenário. Se não se pode mudar a realidade da doença da criança e o sofrimento de seus familiares, pelo menos que se faça algum esforço para amenizar as demais fontes de sofrimento para eles (Santos et al., 2013).

A classe hospitalar tem uma ligação com a escola de origem por meio das atividades e dos programas enviados para serem trabalhados com o educando e dos relatórios encaminhados à escola de origem, que servem como avaliação. Não existindo esse elo, o atendimento pedagógico no hospital teria seu sentido minimizado, por não garantir a continuidade escolar e o passar de ano dos alunos (Cohen e Melo, 2010).

Para tanto, é necessário que haja um convênio entre o hospital e a escola mediante a parceria entre as secretarias estaduais ou municipais de Educação e de Saúde. Entretanto, embora previsto no item 9 da resolução n. 41/95 (Brasil, 1995) que as crianças e os adolescentes hospitalizados precisam de acompanhamento pedagógico, os órgãos públicos, os educadores, os hospitais e a sociedade conhecem pouco sobre as atividades educativas no contexto hospitalar como uma modalidade oficial de ensino em nosso país (Holanda e Collet, 2011).

Os sujeitos desta pesquisa que não estavam em atraso escolar, isto é, que cursavam uma série inadequada para sua idade, conseguiram obter aprovações pela compreensão e parceria da escola, que entendia a condição de saúde e doença dos escolares e permitia a realização de provas em outros momentos, para que eles não fossem prejudicados. Essa modalidade de atendimento representa uma iniciativa fundamental para a humanização e a integralidade do cuidado prestado às crianças e aos adolescentes hospitalizados. Portanto, faz-se necessário que toda instituição de saúde que presta assistência à população infantil tenha um atendimento educacional pedagógico interligado com as escolas, para dar continuidade à educação formal dessas crianças e desses adolescentes. 


\section{Considerações finais}

Os resultados desta pesquisa revelam alguns sentimentos, percepções e necessidades de crianças e adolescentes em condição crônica hospitalizados em relação ao seu adoecimento e processo de escolarização. A tristeza emanada durante a internação, associada à saudade da escola, gera imenso sofrimento nessas pessoas.

Apesar de o hospital estudado desenvolver alguns projetos de apoio pedagógico fundamental durante a internação, ainda não oferece nenhum acompanhamento formal do currículo escolar das crianças e dos adolescentes. As atividades realizadas estão muito voltadas para o aspecto lúdico, o que é essencial durante o internamento, por proporcionar e garantir um direito legal de recreação e lazer dos pacientes, porém isuficiente para suprir as necessidades educacionais.

Considera-se, portanto, essencial que os hospitais infantis ofereçam um acompanhamento pedagógico e educacional por meio da classe hospitalar a fim de dispor de uma assistência humanizada e integral às crianças e aos adolescentes que têm seu processo de escolarização interrompido com a internação hospitalar. A continuidade dos estudos dentro do hospital, além de ajudar a criança ou o adolescente a superar esse período, contribui para que ele se sinta incluído na sociedade.

Ressalte-se que, apesar das limitações desta pesquisa - como ter se restringido a ouvir as crianças e os adolescentes, sem a abrangência de gestores hospitalares e educacionais, profissionais de saúde e familiares -, ela fornece aporte para que se compreenda melhor a importância da implantação da classe hospitalar, de forma a se promover o direito de estudar, mesmo diante da fragilidade do adoecimento e do processo de hospitalização, tornando esse momento menos amedrontador e triste para crianças e os adolescentes cronicamente adoecidos.

\section{Colaboradores}

Mayara Kelly Moura Ferreira idealizou o estudo em termos teóricos e metodológicos, analisou os dados da literatura, coletou os dados, elaborou a discussão e redigiu o texto. Ilvana Lima Verde Gomes idealizou o estudo em termos teóricos e metodológicos e participou na análise e discussão dos dados e na redação do texto. Sarah Vieira Figueiredo participou na discussão e na redação do texto. Maria Veraci Oliveira Queiroz e Viviane Peixoto Santos Pennafort colaboraram na redação do texto. 
Resumen Este artículo tuvo como objetivo identificar las propuestas de escolarización en el ambiente hospitalario, su implementación dirigida a los niños y adolescentes con enfermedad crónica y comprender la percepción de ellos acerca de su escolarización en ese ambiente. Se desarrolló una investigación en un hospital de referencia pediátrica de Fortaleza, estado de Ceará, Brasil, en el período de marzo a mayo de 2013, por medio de entrevista semiestructurada, con ocho niños y adolescentes internados con condición crónica. Los datos se sometieron a análisis, clasificándolos en dos categorías: percepción de niños y adolescentes hospitalizados acerca de su escolarización; y distanciamiento entre teoría y práctica en la escolarización de niños y adolescentes hospitalizados. Se observó que la tristeza emanada durante la internación de niños y adolescentes, asociada a la salud y al alejamiento de la escuela, las restricciones impuestas en las rutinas establecidas por la institución y la condición clínica generaron un enorme sufrimiento en esas personas. Poco se hace sobre la escolarización de estos individuos, pues las actividades lúdicas y educativas llevadas a cabo por los profesionales de la salud no atienden esta necesidad. Así, concluimos que es esencial que la unidad hospitalaria ofrezca un acompañamiento educativo para esta clientela, dando continuidad al proceso de escolarización por medio de la clase hospitalaria, a fin de ofrecer una asistencia integral que satisfaga las prerrogativas prescritas en la legislación.

Palabras clave escolaridad; enfermedad crónica; asistencia integral a la salud; niño hospitalizado; adolescente hospitalizado.

\section{Notas}

1 Universidade Federal do Ceará, Fortaleza, Ceará, Brasil.

$<$ mayarakelly_ferreira@hotmail.com>

Correspondência: Rua Natal, 1.185, Bairro Henrique Jorge, CEP 60521-092, Fortaleza, Ceará, Brasil.

2 Universidade Estadual do Ceará, Programa de Pós-Graduação em Saúde Coletiva, Fortaleza, Ceará, Brasil.

$<$ ilverde@gmail.com>

3 Universidade Estadual do Ceará, Programa de Pós-Graduação em Saúde Coletiva, Fortaleza, Ceará, Brasil.

<sarahvfigueiredo@gmail.com>

4 Universidade Estadual do Ceará, Programa de Pós-Graduação Cuidados Clínicos em Enfermagem e Saúde, Departamento de Enfermagem, Fortaleza, Ceará, Brasil.

$<$ veracioq@hotmail.com>

5 Universidade Estadual do Ceará, Programa de Pós-Graduação Cuidados Clínicos em Enfermagem e Saúde, Fortaleza, Ceará, Brasil.

<vivipspf@yahoo.com.br> 
6 Este artigo foi extraído da monografia Criança e adolescente cronicamente adoecidos: escolarização durante a internação hospitalar, de Mayara Kelly Moura Ferreira, apresentada no Curso de Graduação em Enfermagem da Universidade Estadual do Ceará (UECE). A pesquisa que originou a monografia obteve aprovação do Comitê de Ética em Pesquisa da UECE e do hospital em estudo, de acordo com os pareceres n. 251.490 e n. 794/2011, respectivamente. Não há conflito de interesses entre os autores.

\section{Referências}

ALBERTONI, Léa C.; GOULART, Barbara N. G.; CHIARI, B. M. Implantação de classe hospitalar em um hospital público universitário de São Paulo. Revista Brasileira de Crescimento e Desenvolvimento Humano, São Paulo, v. 21, n. 2, p. 362-367, 2011. Disponível em: <http:// pepsic.bvsalud.org/pdf/rbcdh/v21n2/19.pdf $>$. Acesso em: 12 ago. 2012.

ARAÚJO, Yana B. et al. Conhecimento da família acerca da condição crônica na infância. Texto \& Contexto Enfermagem, Florianópolis, v. 18 , n. 3, p. 498-505, jul./set. 2009. Disponível em: <www.scielo.br/pdf/tce/v18n3/ al3v18n3.pdf>. Acesso em 21 out. 2012.

ARAÚJO, Yana B. et al. Enfrentamento do adolescente em condição crônica: importância da rede social. Revista Brasileira de Enfermagem, Brasília, v. 64, n. 2, p. 281-286, mar./abr. 2011. Disponível em: <www.scielo. br/pdf/reben/v64n2/a10v64n2.pdf $>$. Acesso em: 21 out. 2012.

BARROS, Alessandra S. S.; GUEUDEVILLE, Rosane S.; VIEIRA, Sônia C. Perfil da publicação científica brasileira sobre a temática da classe hospitalar. Revista Brasileira de Educação Especial, Marília, v. 17, n. 2, p. 335-354, maio/ago. 2011.

BORBA, Regina I. H. et al. O mundo da criança portadora de asma grave na escola. Acta Paulista de Enfermagem, São Paulo, v. 22 (especial 70 anos), p. 921-927, 2009. Disponível em: $<$ www.scielo.br/pdf/ape/v22nspe/15.pdf>. Acesso em: 15 set. 2012.
BRASIL. Lei n. 8.069, de 13 de julho de 1990: Estatuto da Criança e do Adolescente (ECA). Fortaleza: Conselho Estadual dos Direitos da Criança e do Adolescente do Ceará, 1991. Disponível em: <www.planalto.gov. br/ccivil_03/LEIS/L8069.htm>. Acesso em: 14 ago. 2012.

BRASIL. Conselho Nacional de Defesa dos Direitos da Criança e Adolescente (BR). Resolução n. 41, 13 de outubro de 1995. Dispõe sobre os direitos da criança hospitalizada. Diário Oficial da República Federativa do Brasil, Brasília, DF, seção I, p. 16.319-16.320, 17 out. 1995. Disponível em: <www.mp.rs.gov. br/infancia/legislacao/id2178.htm $>$. Acesso em: 14 ago. 2012.

BRASIL. Ministério da Educação. Secretaria de Educação Especial. Classe hospitalar e atendimento pedagógico domiciliar: estratégias e orientações. Brasília, DF: MEC/Seesp, 2002. Disponível em: <http://portal.mec.gov. br/seesp/arquivos/pdf/livro9.pdf $>$. Acesso em: 15 set. 2012 .

BRASIL. Lei n. 9.394, de 20 de dezembro de 1996. Estabelece as Diretrizes e Bases da Educação Nacional. 9. ed. Brasília: Câmara dos Deputados, Coordenação Edições Câmara, 2014. Disponível em: <www.famasul.edu. br/2015/arquivos_pdf/106.pdf $>$. Acesso em: 2 ago. 2015.

BRASIL. Resolução n. 466, de 12 de dezembro de 2012. Dispõe sobre as diretrizes e normas regulamentadoras de pesquisas envolvendo 
seres humanos. Plenário do Conselho Nacional de Saúde. Brasília, DF, 12 dez. 2012. Disponível em: <http://bvsms.saude.gov.br/ bvs/saudelegis/cns/2013/res0466_12_12_ 2012.html>. Acesso em: 14 jun. 2013.

COHEN, Ruth H. P.; MELO, Amanda G. S. Entre o hospital e a escola: o câncer em crianças. Estilos da Clínica, São Paulo, v. 15, n. 2, p. 306-325, dez. 2010. Disponível em: <http:// pepsic.bvsalud.org/pdf/estic/v15n2/a03v15n2. pdf>. Acesso em: 14 ago. 2012.

COSTA, Jaquilene B.; MOMBELLI, Mônica A.; MARCON, Sonia S. Avaliação do sofrimento psíquico da mãe acompanhante em alojamento conjunto pediátrico. Estudos de Psicologia, Campinas, v. 26, n. 3, p. 317-325, jul./set. 2009. Disponível em: <www.scielo. br/pdf/estpsi/v26n3/v26n3a05.pdf>. Acesso em: 9 out. 2013.

GOMES, Ilvana L. V. A criança hospitalizada, seus direitos e as relações interpessoais no cuidado e tratamento: caminhos e descaminhos. 219 fls. Tese (Doutorado em Medicina Social) - Instituto de Medicina Social, Universidade do Estado do Rio de Janeiro, Rio de Janeiro, 2007.

HOLANDA, Eliane R.; COLLET, Neusa. As dificuldades da escolarização da criança com doença crônica no contexto hospitalar. Revista da Escola de Enfermagem da USP, São Paulo, v. 45, n. 2, p. 381-389, abr. 2011. Disponível em: <www.scielo.br/pdf/reeusp/ v45n2/v45n2all.pdf $>$. Acesso em: 12 ago. 2012.

HOLANDA, Eliane R.; COLLET, Neusa. Escolarização da criança hospitalizada sob a ótica da família. Texto \& Contexto Enfermagem, Florianópolis, v. 21, n. 1, p. 34-42, jan./mar. 2012. Disponível em: <www.scielo. $\mathrm{br} / \mathrm{pdf} / \mathrm{tce} / \mathrm{v} 2 \mathrm{ln} 1 / \mathrm{a} 04 \mathrm{v} 2 \mathrm{ln} 1 . \mathrm{pdf}>$. Acesso em: 12 ago. 2012.

HOSPITAL INFANTIL ALBERT SABIN (HIAS). Projetos de humanização. 2013. Disponível em: <www.hias.ce.gov.br>. Acesso em: 3 jun. 2013.
LEOPARDI, Maria T. Metodologia da pesquisa na saúde. 2. ed. Santa Maria, RS: Pallotti, 2002.

MINAYO, Maria C. S. (org.). Pesquisa social: teoria, método e criatividade. Petrópolis: Vozes; 2010.

SANTOS, Leidiene F. et al. Reflexos da hospitalização da criança na vida do familiar acompanhante. Revista Brasileira de Enfermagem, Brasília, v. 66, n. 4, p. 473-478, jul./ago. 2013.

SCHNEIDER, Karine L. K.; MARTINI, Jussara G. Cotidiano do adolescente com doença crônica. Texto \& Contexto Enfermagem, Florianópolis, v. 20, n. esp. p. 194-204, 2011. Disponível em: <www.scielo.br/pdf/tce/ v20nspe/v20nspea25.pdf >. Acesso em: 10 maio 2012.

SILVA, Maria G. N. Doenças crônicas na infância: conceito, prevalência e repercussões emocionais. Revista de Pediatria do Ceará, Fortaleza, v. 2, n. 2, p. 29-32, maio/ago. 2001. Disponível em: <www.socep.org.br/ Rped/pdf/2.2\%20Atualiz\% 2003.pdf $>$. Acesso em: 14 set. 2012.

ZOMBINI, Edson V. Classe hospitalar: uma estratégia para a promoção da saúde da criança. 152 fls. Dissertação (Mestrado em Saúde Pública) - Faculdade de Saúde Pública da Universidade de São Paulo, São Paulo, 2011. Disponível em: <www.teses.usp.br/teses/ disponiveis/6/6135/tde-15042011-090424/ pt-br.php>. Acesso em: 10 maio 2012.

ZOMBINI, Edson V. et al. Classe hospitalar: a articulação da saúde e educação como expressão da política de humanização do SUS. Trabalho, Educação e Saúde, Rio de Janeiro, v. 10, n. 1, p. 71-86, mar./jun. 2012. Disponível em: <www.scielo.br/pdf/tes/v10nl/ v10nla05.pdf>. Acesso em: 14 set. 2012.

Recebido em 31/01/2014

Aprovado em 15/05/2014 